Carter collected the cases reported to date. They were twenty-ninc in number. The develomment of the condition scems to be about as follows: The child secms perfectly normal at birth. It continues to be normal for three weeks to a month, and then ceases to take any interest in its surroundings. It is often sleepless: it rolls its eyes more or less continuously, and is generally restless. When it should latre strength enough to sit up. it fails to do so. It slides down on its back instead of sitting up, but does not fall forward or sieleways. Vermicular motions in the fingers somewhat resembling the movenents of athetosis have been noted. The tendeney to sommoleney becomes more marlich. Hydrocephalus has been known to develop. Diplegia exists at times, and a spastic condition of the lower limbs has been noted. The clectric reactions are normal. At the end of a year the child is totally blind, the optic nerve is of a dead-white color, more or less marlicd idiocy has asserted itself, and distinet palsy is prescnt. Marasmus usually closes the scene before the end of the sccond year. The marked differential sign of the disease is the oceurrence of idiocy in connection with blindncss.

In a recent case seen by Dr. Claiborne the ehild was normal at birth and remained so up to the ninth month. Then an external squint was notcd in the right eyc. After this ptosis oceurred in this cye. Then a sinilar train of symptoms developed in the other eyc. The family history showed that the father died of tuberculosis. There was no syphilitic history, yet mercurial inunetions were tricd on general principles, and after a while the ptosis disappeared and the squint was modified. Narasmus developed, howerer. and the intelligence decreased very marledly. As the malnutrition advaneed the cye symptoms rccurred, and finally death from exhaustion ensucd. At the autopsy a tubcrcular tumor of the corpora quadrigemina was found. There was also gencribulous nodules were found in the lungs, spleen, and the bronchial glands. Curiously enough this case was not of Hebrew origin. All the subjects of a maurotic fanlily idiocy up to this one were Hebraic. In another case under Dr. Claiborne's care the subject was also not of the Hebrew racc. The existence of the tubercle at the base of the brain is cxtremely interesting. It is possible that in most of the cases some such lesion has been presat lcast it is siggestive to find that a tubercle can cause a set of symptoms that resemble annaurotic family idiocy so much.

The differential diagnosis is not diffienlt as a rule. Freidreich and Marie's ataxia in their hereditary form may be confounded. The pathogonomic sign is a condition of the fundus in the amaurotic family idiocy. The fact that death takes place from marasmus probably points to the tubereulous cliaracter of the affection. This characteristic has been missed so far beeause too much attention has been directed to the central nervous system, espeeially to the cortex. The suggested pathology of the disease up to this has been some disturbance of the cortcx, while the ganglia at the base of the brain and the medulla were considered to be normal. Amaurotic family idioey is evidently not so rarc as has becn thought. Seven eases have been under trcatment at the Vanderbilt clinic. All of these were Polish Jews, and there was no history of phthisis or of consanguinity in the parents. JELLIFFE.

149 Prognose und Therapie Gehirn Lues (The Prognosis and Therapeutics of Syphilis of the Brain). v. Hösslin (Deutsch. Archiv. f. klin. Med., Dec. 13, 1899, Vol. 66, p. 28I).

v. Hösslin reports II cases with 2 deaths. The symptoms were various, some of the patients having attacks resembling epilepsy; 
others having attaclis rescubing apoplexy and hemplegia, and whe gatticht, ater alpparent complete cure. developed paretie dementia it year later. Several of the onhers hatd slight relapses, which were reseliiy

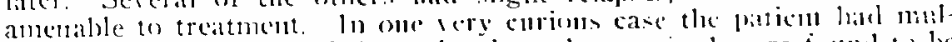

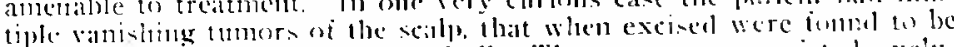

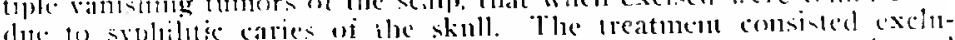

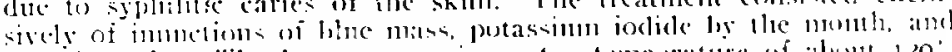

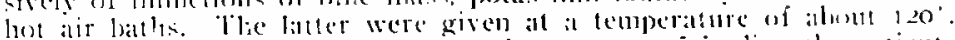

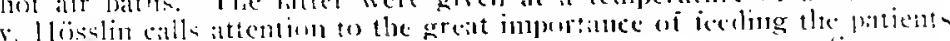
in il state of combl thrmigh the esoplatigea! tobe.

S.MII.K.

\section{l.ATllol. (3)}

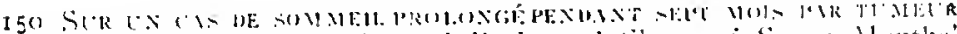

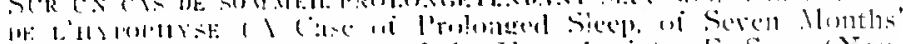
Duration, (atised ly lumor of the Ilypoplysin). If. Socal (Sou-

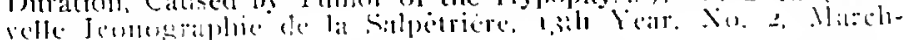
April, 1000, 12. 1011).

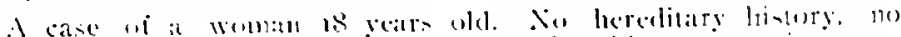

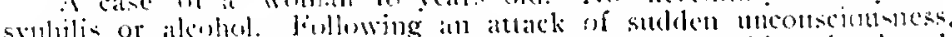

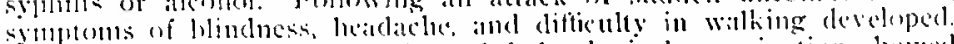

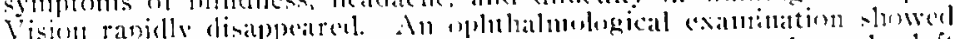

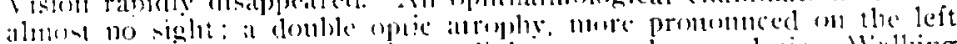

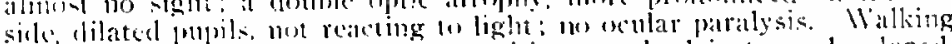

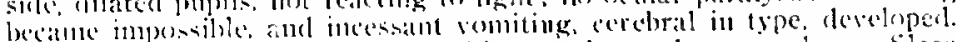

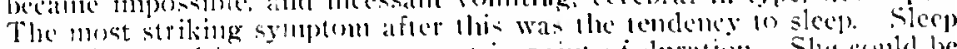

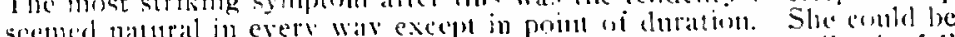

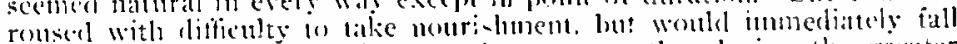

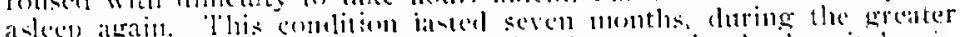
pat of which the pateme slept. During her stay it the hospitit pain

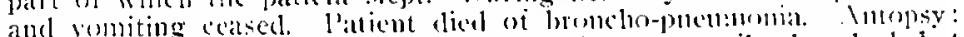

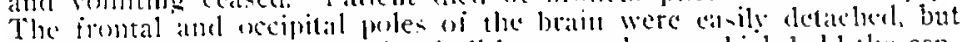

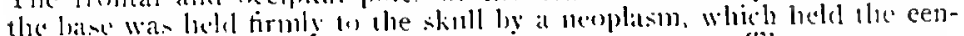
tral part of ihe hite of the brain to the dura matcr. The tumser cos:-

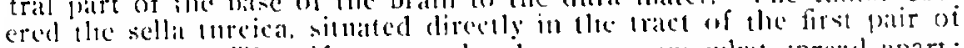
eranial nerres. fle olfachory peduncles were womewlat spread apart;

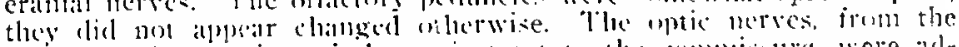

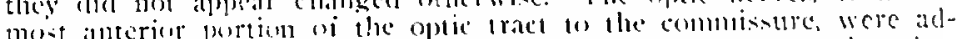

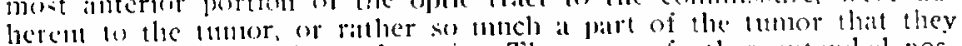

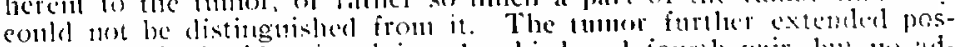

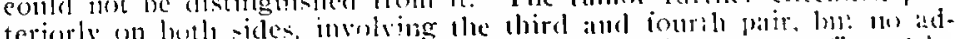

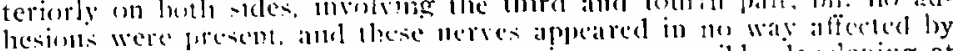

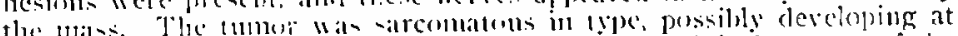

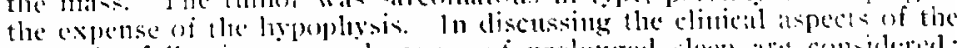

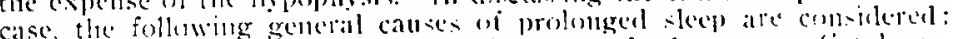

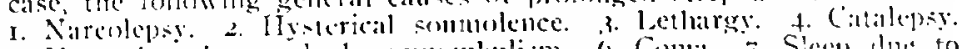

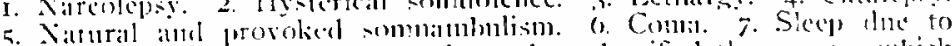

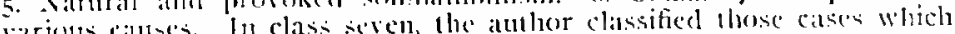

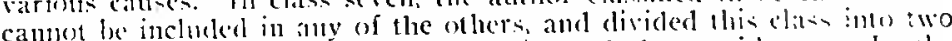

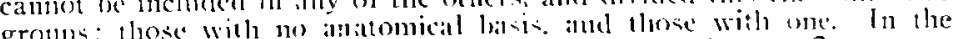

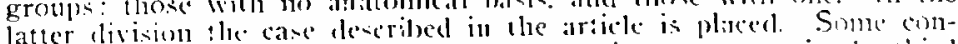
siderition is given to tinc absence of compresion symplons in the third and iourale neres and peduncles. The autlow finds the explanation in

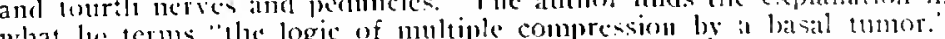

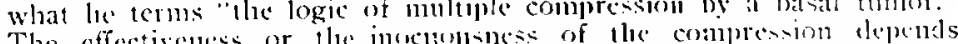

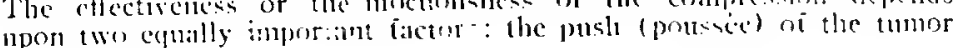

